\title{
SOBRE EL STATUS ONTOLÓGICO DE LOS DERECHOS HUMANOS
}

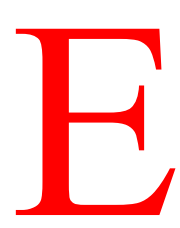

1 problema de los derechos humanos no solamente se ha convertido en nuestra época en un tema central de la discusión teórica, en la que participan activamente representantes de diversas disciplinas (juristas, filósofos, politólogos, etc.); desde el punto de vista de la política se trata de una cuestión sumamente actual, cuya importancia práctica dificilmente podría ser exagerada.

En el transcurso del desarrollo de la teoría de los derechos humanos fueron ofrecidas distintas propuestas para su fundamentación. Casi todas estas propuestas parten del supuesto de que los derechos humanos no pueden tener su fundamento (exclusivo) en el derecho positivo, pues la idea de derechos humanos cobra especial importancia cuando tales derechos son violados o no reconocidos por los ordenamientos jurídicos positivos. Para usar un ejemplo de Nino ${ }^{1}$ : cuando en nombre de los derechos humanos se acusa a la Unión Soviética de no admitir otros partidos políticos que el partido comunista, la respuesta de que el orden jurídico de ese país prohíbe otros partidos sería claramente insatisfactoria. La razón es clara: una respuesta de este tipo, de ser verdadera, sólo confirmaría la legitimidad de la crítica. En este sentido parece claro que los derechos humanos no pueden reducirse a la regulación normativa, de un orden jurídico positivo, pues ellos ofrecen justamente el marco dentro del cual es posible la crítica de las leyes o instituciones del derecho positivo. De aquí parece inferirse que cuando un orden jurídico positivo otorga derechos humanos, en realidad no hace otra cosa que reconocer derechos ya preexistentes e independientes de lo que establece el orden jurídico en cuestión. Ahora bien ¿qué son estos derechos independientes del orden jurídico?

Las primeras formulaciones históricas de los derechos humanos en la segunda mitad del siglo XVIII (Bill of Rights de la Constitución de Virginia, 1776, la declaración francesa de los derechos humanos de 1789) invocan expresamente el derecho natural. Los derechos humanos son concebidos como derechos otorgados por el derecho natural y su existencia no depende del derecho positivo. Lo único que queda al legislador es su reconocimiento.

En el transcurso del siglo XIX esta fundamentación de los derechos humanos perdió gran parte de su fuerza de convicción cuando el positivismo jurídico se convirtió en la concepción jusfilosófica dominante. Sin embargo, esta situación no fue vivida como una pérdida, porque los derechos

(1) Nino, Carlos S., Ética y Derechos Humanos, Buenos Aires, 1984, p. 24. 
humanos fueron recepcionados bajo la forma de derechos y garantías constitucionales por la mayoría de los órdenes jurídicos positivos y tuvieron reconocimiento práctico por lo menos en el mundo «civilizado». (Por mundo civilizado se entendía en aquella época fundamentalmente Europa y los Estados Unidos; qué ocurría en otras partes del mundo, interesaba poco).

Recién con la aparición de los regímenes totalitarios en los años veinte y treinta de este siglo, regímenes que suprimieron en forma decidida los derechos y garantías constitucionales, se sintió una urgente necesidad de proporcionar a los derechos humanos una fundamentación más sólida que el mero derecho positivo para poder proteger esos derechos contra los regímenes totalitarios. A ello se agregó, además, la ampliación del mundo «civilizado». Ahora ya no puede ser contemplado con indiferencia lo que ocurre en Chile, África del Sur o en Corea.

Un problema práctico, la urgente necesidad de justificar el castigo de los crímenes del Tercer Reich, originó en los años cincuenta, es decir, pocos años después de la terminación de la Segunda Guerra Mundial, una reacción contra el positivismo dominante hasta entonces, que condujo a una especie de renacimiento del derecho natural, sobre todo en Alemania. Pero es dudoso que la invocación del derecho natural era capaz de suministrar una fundamentación teóricamente satisfactoria (y no sólo psicológicamente convincente) para el mencionado problema práctico ${ }^{2}$. En todo caso en la polémica de los años cincuenta se encuentran muy pocos argumentos racionales contra el positivismo jurídico; la mayoría de los ataques al positivismo descansan en confusiones conceptuales. Así, por ejemplo, se ha atribuido a todos los positivistas ciertas doctrinas que en el mejor de los casos fueron sostenidas por algún epígono, pero que jamás fueron compartidas por las figuras rectoras del positivismo jurídico moderno como Hans Kelsen, Alf Ross, H. L. A. Hart o Norberto Bobbio. En efecto, se ha sostenido más de una vez que para el positivismo todo derecho positivo y en particular toda norma jurídica emanada del poder estatal es válida en el sentido de que debe ser obedecida, cualquiera que sea su contenido. Basándose en argumentos de este tipo se acusó al positivismo de haber facilitado el advenimiento del régimen nazi, olvidando que los ideólogos del nacionalsocialismo solían invocar el derecho natural para justificar las tropelías jurídicas del Führer y sus secuaces ${ }^{3}$. En realidad, el positivismo jurídico como teoría filosófica nada tiene que ver con las ideologías políticas y como bien decía Hume no hay peor argumento contra una teoría científica o filosófica que señalar sus presuntas consecuencias políticamente perniciosas.

(2) Cfr. Hart, H. L. A., «Positivism and the separation of law and morals», Harvard Law Review, vol. 71, n. ${ }^{\circ}$ 4, 593-629. (Trad. castellana de Genaro R. Carrió, «El Positivismo jurídico y la separación entre el derecho y la moral» en H. L. H. Hart, Derecho y Moral, ed. Depalma, Buenos Aires, 1962).

(3) Cfr. Garzón Valdés, Ernesto, Derecho y «Naturaleza de las Cosas», vol. II, Córdoba, 1971. 
No es de extrañar pues que este «renacimiento» del derecho natural no haya durado mucho tiempo. Autores como Kelsen, Ross, Hart y Bobbio ${ }^{4}$ se encargaron de poner las cosas en su sitio. De todos modos esta polémica tuvo también su lado positivo: los positivistas se vieron obligados a clarificar el concepto de positivismo jurídico para definirlo con mayor precisión. De esta manera salieron a la luz diferentes y a veces incompatibles tesis que fueron sostenidas por distintos positivistas. Esto lleva a la distinción entre varios tipos de positivismo; un trabajo paradigmático en tal sentido es el de Bobbio ${ }^{5}$.

Sin embargo, en los últimos tiempos se ha producido un nuevo renacimiento de las teorías jusnaturalistas, aunque sus protagonistas rara vez utilizan el término «derecho natural» para referirse a sus doctrinas. Este resurgimiento del derecho natural comienza con Ronald Dworkin, quien lanzó ya en los últimos sesenta su famoso ataque al positivismo de Hart $^{6}$. En los últimos años se ha incrementado notoriamente el número de pensadores que cabe calificar como partidarios del derecho natural: Rawls y Nozick en los Estados Unidos, Finnis en Inglaterra y Carlos Nino en la Argentina son quizás sus representantes más notorios. Todos estos autores se ocupan de derechos y en particular de los derechos humanos. En lo que sigue me referiré en especial al libro de Nino Ética y Derechos Humanos $^{7}$.

¿Cómo fundamenta un autor moderno como Nino los derechos humanos? Nino comienza por señalar que el concepto de derecho subjetivo está referido a normas: proposiciones acerca de derechos subjetivos en general y de derechos humanos en particular son equivalentes a proposiciones acerca del contenido de las reglas o principios de un determinado sistema de normas (p. 23).

En esto Nino tiene sin duda razón. En el caso especial de los derechos humanos se trata de reglas o principios de un sistema moral. Por lo tanto los derechos humanos son, al menos en su sentido originario, derechos morales. Llegamos, pues, a la conclusión de que los derechos humanos otorgados por un orden jurídico son derechos morales, que el orden jurídico en cuestión reconoce, pero cuya existencia es independiente de ese reconocimiento.

(4) Cfr. Kelsen, Hans, «Naturrechtslehre und Rechtspositivismus» en Revista Jurídica de Buenos Aires, 1961-IV, pp. 8-45 (con traducción castellana de Eugenio Bulygin); Ross, Alf, «Validity and the conflict between legal positivism and Natural Law», ibídem, pp. 46-93 (con trad. castellana de Genaro R. Carrió v Osvaldo Paschero); Hart, H. L. A., op. cit., en nota 2, y Bobbio, Norberto, El problema del positivismo jurídico (trad. castellana de Ernesto Garzón Valdés), Buenos Aires, 1965.

(5) Cfr. el libro citado en la nota anterior.

(6) Cfr. Dworkin, Ronald, «Is Law a System of Rules?» en R. M. Dworkin, The Philosophy of Law, Oxford, 1977, (publicado originariamente en 1967 bajo el título «The Model of Rules», 35 University of Chicago Law Review 14).

(7) Op. cit. nota 1. 
Cuando Nino habla de sistema moral no se trata de un sistema de moral positiva, es decir de una moral vigente de hecho en una sociedad determinada en un momento determinado, sino de una moral ideal o crítica. La moral ideal es para Nino un sistema de principios y juicios de valor que poseen validez objetiva, es decir, valen en todo tiempo y lugar, con independencia de su reconocimiento fáctico, y que son accesibles a la razón humana. De esta caracterización surge claramente que tal sistema moral no se distingue de un sistema de derecho natural, cosa que Nino admite sin tapujos (p. 25).

La fundamentación de los derechos humanos descansa, pues, en la hipótesis de un sistema moral objetivamente válido, accesible al conocimiento humano. No voy a examinar aquí las razones que da Nino en favor de la aceptación de esta hipótesis (aunque no puedo dejar de reconocer que estas razones no acaban de convencerme). Pero Nino cree que esta hipótesis también es aceptable para un positivista jurídico, al menos para un positivista conceptual, por oposición a un positivista ideológico. Para poder analizar esta afirmación de Nino es indispensable definir con claridad los conceptos de jusnaturalismo y positivismo, decisivos en este contexto.

El jusnaturalismo puede ser definido (y es definido también por Nino) mediante las siguientes dos tesis: a) La primera tesis afirma la existencia de un derecho natural, es decir, de un sistema de normas universalmente válidas y cognoscibles que suministran criterios para la justicia de instituciones sociales; b) La segunda tesis afirma que un sistema normativo que no se ajusta al derecho natural (esto es, se halla en conflicto con él) no es un orden jurídico.

La primera es una tesis ontológica; en cambio, la segunda tesis puede ser considerada como una tesis semántica, pues ella limita la extensión del concepto de derecho y sirve, por lo tanto, para la determinación del significado de la palabra «derecho».

Nino caracteriza el positivismo conceptual como la posición que niega la segunda, pero no la primera tesis del jusnaturalismo. Este tipo de positivismo se reduce, por lo tanto, conforme a Nino, a una propuesta semántica: a saber, usar la palabra «derecho» en un sentido más amplio, de modo que también los sistemas normativos injustos, es decir, que contradicen el derecho natural puedan ser llamados «derecho». No es de extrañar, pues, que toda la polémica entre los positivistas y los partidarios del jusnaturalismo se reduzca para Nino a una pseudodiscusión acerca del significado de palabras.

La conveniencia de la definición del positivismo propuesta por Nino resulta dudosa, pues la mayoría de los autores de cuño positivista consideran que su posición es incompatible con la creencia en la existencia de un derecho natural. Por ejemplo, autores como Kelsen, Ross y Hart (y también von Wright) consideran la negación de la tesis (a) como una característica definitoria del positivismo jurídico. Por el contrario, el positivismo jurídico, tal como lo define Nino, resulta compatible con la aceptación del derecho natural. Nino cree que la negación de la tesis (a) no es característica definitoria del positivismo jurídico, sino del escepticismo 
ético. El escéptico en ética en el sentido de Nino no cree en la posibilidad de poder identificar un sistema normativo justo y universalmente válido (llámese éste derecho natural o moral ideal), sea porque tal sistema no existe (escepticismo ontológico), sea porque no es accesible para la razón humana (escepticismo gnoseológico).

Personalmente prefiero considerar el escepticismo ético como una característica definitoria del positivismo jurídico. Es interesante observar que un filósofo como G. H. von Wright, quien tiene poco que ver con el positivismo jurídico, caracteriza este último a través de las siguientes tres tesis: (1) Todo derecho es derecho positivo (creado por los hombres); (2) distinción tajante entre proposiciones descriptivas y prescriptivas (ser y deber), y (3) la concepción no cognoscitiva de las normas, que no pueden ser verdaderas ni falsas. Estas tres tesis implican que no puede haber normas verdaderas (ni jurídicas, ni morales) y por consiguiente no hay derecho natural. Si esto es considerado como escepticismo ético, entonces este último es una característica definitoria del positivismo jurídico en la concepción de von Wright.

Naturalmente, no tiene sentido discutir sobre el significado de las palabras y por lo tanto es en principio indiferente si el positivismo jurídico es definido como una tesis puramente semántica o como una tesis sustantiva. La pregunta interesante en este contexto es: ¿qué son los derechos humanos, es decir, cuál es su status ontológico para un positivista (en mi sentido del término) o para un escéptico ético en el sentido de Nino?

Es claro que si no hay normas morales absolutas, objetivamente válidas, tampoco puede haber derechos morales absolutos y, en particular, derechos humanos universalmente válidos. ¿Significa esto que no hay en absoluto derechos morales y que los derechos humanos sólo pueden estar fundados en el derecho positivo? Esta pregunta no es muy clara y no cabe dar una respuesta unívoca.

Por un lado, nada impide hablar de derechos morales y de derechos humanos, pero tales derechos no pueden pretender a una validez absoluta. Ellos sólo pueden ser interpretados como exigencias que se formulan al orden jurídico positivo desde el punto de vista de un determinado sistema moral. Si un orden jurídico positivo cumple o no efectivamente con esas exigencias es una cuestión distinta, que sólo puede ser contestada en relación a un determinado orden jurídico y un determinado sistema moral.

Por lo tanto, los derechos humanos no son algo dado, sino una exigencia o pretensión. Recién con su «positivización» por la legislación o la constitución los derechos humanos se convierten en algo tangible, en una especie de realidad, aun cuando esa «realidad» sea jurídica. Pero cuando un orden jurídico positivo, sea éste nacional o internacional, incorpora los derechos humanos, cabe hablar de derechos humanos jurídicos y no ya meramente morales.

Se me podría reprochar que esta concepción de los derechos humanos los priva de cimientos sólidos y los deja al capricho del legislador positivo. Por lo tanto, la concepción positivista de los derechos humanos 
sería políticamente peligrosa. Sin embargo, no veo ventajas en cerrar los ojos a la realidad y postular un terreno firme donde no lo hay. Y para defenderme del ataque podría retrucar que es políticamente peligroso crear la ilusión de seguridad, cuando la realidad es muy otra. Si no existe un derecho natural o una moral absoluta, entonces los derechos humanos son efectivamente muy frágiles, pero la actitud correcta no es crear sustitutos ficticios para tranquilidad de los débiles, sino afrontar la situación con decisión y coraje: si se quiere que los derechos humanos tengan vigencia efectiva hay que lograr que el legislador positivo los asegure a través de las disposiciones constitucionales correspondientes y que los hombres respeten efectivamente la constitución.

Por eso, la fundamentación de los derechos humanos en el derecho natural o en una moral absoluta no sólo es teóricamente poco convincente, sino políticamente sospechosa, pues una fundamentación de este tipo tiende a crear una falsa sensación de seguridad: si los derechos humanos tienen una base tan firme, no hace falta preocuparse mayormente por su suerte, ya que ellos no pueden ser aniquilados por el hombre. Para la concepción positivista, en cambio, los derechos humanos son una muy frágil, pero no por ello menos valiosa conquista del hombre, a la que hay que cuidar con especial esmero, si no se quiere que esa conquista se pierda, como tantas otras.

La discusión en torno a la fundamentación de los derechos humanos presenta una marcada analogía con la que se suscitó al comienzo de la edad moderna y muy especialmente en la Ilustración respecto de la existencia de Dios. También en aquella época se esgrimió el argumento de que sin Dios el hombre se encontraría solo en medio de un universo hostil y la vida no tendría sentido. Pero si Dios no existe, de nada vale postular su existencia y fomentar la fe. Hay que probar la existencia de Dios de una manera independiente de las tristes consecuencias que acarrearía su ausencia. Y si tal prueba no se produce, la actitud racional consiste en afrontar la realidad, exactamente como en el caso de los derechos humanos. 